\title{
A EDUCOMUNICAÇÃO EM CUBA: EXPERIÊNCIAS, REFLEXÕES E PERSPECTIVAS
}

\author{
EDUCOMUNICATION IN CUBA: \\ EXPERIENCES, REFLECTIONS AND PERSPECTIVES
}

\author{
Felipe Chibas Ortiz(*) \\ Universidade de São Paulo, São Paulo, Brasil.
}

Resumo: Neste artigo apresenta-se um resumo de algumas das principais práticas da Educomunicação em Cuba, suas principais tendências e representantes. Mostra-se um excerto das experiências mais significativas da Educomunicação nesse país e realiza-se uma reflexão sobre a projeção futura deste movimento. $\mathrm{O}$ trabalho está embasado na revisão bibliográfica e em documentos internos das organizações pesquisadas, assim como na observação participativa e experiência do autor em muitas das práticas descritas. As conclusões sugerem que a perspectiva da Educomunicação em Cuba está ligada à utilização das novas tecnologias com as manifestações artísticas, assim como no aprofundamento teórico e no debate epistemológico.

Palavras-chave: Educomunicação; Gestão da comunicação; Responsabilidade Social.

Abstract: The present article gives a brief summary about the principal practices of Educomunication in Cuba. It shows the main trends and representatives. Also show the projection and reflection on the future possibilities of this movement in the country. This work is grounded in the literature review and internal documents of the organizations surveyed, as well as participant observation and experience of the author in many of the practices described. The findings suggest that the prospect of the Educomunication in Cuba is linked to the use of new technologies in their artistic expressions, as well as further theoretical and epistemological debate.

Keywords: Educomunication; Communication management; Social responsibility.

${ }^{*}$ ) Doutor, pesquisador da Universidade Federal do Rio Grande do Norte. E-mail: chibas_f@yahoo.es. Recebido em: 22.06.2015; aceito em: 07.12.2015. 


\section{INTRODUÇÃO}

Pensadores, filósofos, educadores, psicólogos, sociólogos e comunicólogos têm produzido análises sobre a realidade contemporânea e a relação das Ciências Humanas e Sociais com a Educação e a Comunicação, tendo como ponto de partida a importância da comunicação na atualidade. Países como Inglaterra, França, Suécia, Espanha, boa parte da América Latina e especialmente o Brasil têm realizado estudos e aplicado o enfoque da Educomunicação sob diferentes plataformas conceituais. A partir da década de 1970 este enfoque também tomou força nos Estados Unidos (SOARES, 2014).

Já a UNESCO declarou, referindo-se a este tipo de estudos, o seguinte:

"[...] todas as formas de estudar, aprender e ensinar a todos os níveis (...) e em todas as circunstâncias, a história, a criação, a utilização e avaliação dos meios de comunicação como artes práticas e técnicas, assim como o lugar que ocupam os meios de comunicação na sociedade, sua repercussão social, as consequências da comunicação mediatizada, a participação, a modificação que produzem no modo de perceber, o papel do processo criador e o acesso a os meios de comunicação ( UNESCO, 1984, p. 45).

Soares (2014) faz um breve histórico da Educomunicação no Brasil e na América Latina, classificando-a nos períodos a seguir:

\section{1960: Plan DENI}

Os primeiros projetos na década de 1960 se voltavam para a análise da produção cinematográfica, promovida pelas paróquias e escolas católicas. Numa iniciativa do pedagogo Luis Campos, chamada Plan DENI (Plan de Niño), se faz uma proposta para exibir e analisar produções cinematográficas com crianças, iniciando-as na compreensão da linguagem audiovisual. A partir de 1969 a OCIC (Organização Católica Internacional de Cinema) assumiu o Plan DENI e o multiplicou em quase todos os países latino-americanos.

\section{Anos 1970: a "leitura crítica da televisão"}

Proliferam neste período pelo continente projetos de educação para a televisão, formação da consciência crítica etc., como forma de reação dos pensadores latino-americanos à crescente influência dos veículos de comunicação social.

III. Ainda nos anos 1970: Comunicação para o desenvolvimento

Neste mesmo período surgem propostas em torno do planejamento participativo e da educação popular, procurando a mudança social. Aqui entram os trabalhos e a prática de Paulo Freire e Mário Kaplún.

IV. Década de 1980: a comunicação como resistência cultural

Acontece nesse período a contribuição da UNESCO no continente na esfera das políticas públicas, no intuito de fazer convergir educação e comunicação, promovendo eventos entre autoridades e pesquisadores, assim como o Projeto Principal de Educação da América Latina e do Caribe. 
V. Década de 1990: a influência dos estudos culturais

Acontece nesta década a manifestação mais explícita da escola dos Estudos Culturais Ingleses, reforçando-se assim o sentido de prática social e não exclusivamente na esfera didática. Consolida-se assim a compreensão do papel ativo do consumidor de mídias enquanto construtor de sentidos no cotidiano.

VI. Virada do milênio: eventos internacionais unem o Hemisfério Norte e a América Latina

Acontecem nesse período eventos internacionais que buscam maior aproximação entre o Hemisfério Norte e a América Latina, como os organizados por Roberto Aparici na Espanha e o I Congresso Internacional de Comunicação e Educação realizado em 1998 em São Paulo, promovido pelo Núcleo de Comunicação e Educação (NCE) da Universidade de São Paulo (USP).

VII. O congresso de São Paulo (1998)

O I Congresso Internacional de Comunicação e Educação, acima mencionado, foi uma linha divisória, dado que se propulsaram ideias inovadoras como as de centralizar a análise da Media education (um dos subtemas da educomunicação) no processo comunicativo e não apenas nos meios. Também se defendeu a ideia de valorizar as ideias e projetos educomunicativos que viessem acompanhadas de experiências práticas.

Mesmo que à distância, os projetos educomunicativos em Cuba acompanharam os processos gerais ocorridos na América Latina (RAMOS, 2001).

A Educomunicação tornou-se um conceito e uma área nova do conhecimento nos finais dos anos 1990 no Brasil, com diversas formas de ser interpretada e colocada em prática (CITELLI, 2011; SOARES, 2009). Entre as diversas linhas adotadas para descrever as inter-relações da comunicação e da educação que são de interesse para este artigo, podemos citar as de Braga e Calazanz (2001), Huergo (2000) e a de Soares (2009). Para Braga e Calazans (2001), a partir dos fins do século XIX a Comunicação vem se tornando uma questão relevante para a sociedade em pelo menos duas arestas. Por um lado, através do desenvolvimento de processos mediáticos que foram gerados na sucessiva diversificação dos meios - penetração do jornal popular, telefone, cinema, rádio, televisão, mais recentemente as redes de informática. Também através da geração de procedimentos públicos de comunicação expressos em profissões e trabalhos como o jornalismo, a publicidade, a criação cinematográfica, radiofônica e televisiva. Por outro lado, o ângulo comunicacional passou a ser relevante no espaço de todas as instituições e atividades da sociedade - na política, na saúde, nos negócios, na literatura, na economia, nas artes, nas ciências sociais e principalmente na educação. Complementam este raciocínio quando dizem:

As interações mais evidentes entre Comunicação e Educação são propostas a partir das intencionalidades educativas - no esforço de aperfeiçoar os processos comunicativos necessários à obtenção de aprendizagem (BRAGA; CALAZANS, 2001, p. 57).

Huergo (2000) foca o processo de inter-relação da educação e a comunicação, vendo-as como áreas diferentes do conhecimento e com interesses distintos, enquanto 
Soares (2009) entende a inter-relação da educação e a comunicação como uma nova área do conhecimento, e foca a Educomunicação no entorno da gestão e das políticas públicas.

Huergo (2000) defende a ideia de "território denso e opaco" onde se interceptam a educação e a comunicação, mas que não definem uma nova área ou paradigma do conhecimento. Por sua parte, Soares define a Educomunicação como:

[...] o conjunto de ações voltadas para a criação de ecossistemas comunicativos abertos e criativos em espaços educativos, favorecedores tanto de relações dialógicas entre pessoas e grupos humanos quanto de uma apropriação criativa dos recursos da informação nos processos de produção da cultura e da difusão do conhecimento. O novo campo apresenta-se como inter-discursivo, inter-disciplinar e mediado pelas tecnologias (SOARES, 2003, p. 5).

Cabe ressaltar que não há muitos trabalhos no Brasil que abordem uma discussão mais teórica, envolvendo a legitimação do campo, mas sim os que relatam as práticas de Educomunicação, como também é o caso do presente texto, onde abordaremos fundamentalmente a aplicação prática em Cuba da linha desenvolvida por Soares.

Uma comparação entre o Paradigma Educacional Tradicional e o Paradigma Educomunicativo pode ser resumida no Quadro 1 ao final deste artigo.

As seis áreas descritas por Soares (2011) como portas de ingresso na Educomunicação são: 1) Educação para a comunicação; 2) Expressão comunicativa por meio das artes; 3) Mediação tecnológica nos espaços educativos; 4) Pedagogia da comunicação; 5) Gestão da comunicação; 6) Reflexão epistemológica sobre a Educomunicação. Para a realização deste trabalho, compreende-se o conceito de Educomunicação como: "[...] um conjunto de ações inerentes ao planejamento, implementação e avaliação de processos, programas e produtos destinados a criar e fortalecer ecossistemas comunicativos" (SOARES, 2011).

O objetivo principal deste artigo é mostrar, sinteticamente, algumas das principais experiências e práticas da Educomunicação em Cuba, assim como refletir sobre a evolução desse conceito nesse país. O trabalho está embasado na revisão bibliográfica e de documentos internos das organizações e entidades pesquisadas, assim como na observação participativa e experiência direta do autor em muitas das práticas descritas. Descrevem-se neste artigo fundamentalmente as experiências de Educomunicação em Cuba referentes ao período compreendido entre finais da década de 1960 até o ano 2015 , embora se mencionem outras referentes a outros períodos.

\section{A COMPREENSÃO DA EDUCOMUNICAÇÃO EM CUBA}

Inicialmente a Educomunicação foi entendida em Cuba, em muitos espaços, como sinônimo de educação audiovisual. Tanto nos meios acadêmicos, como nos meios extra-acadêmicos, a Educomunicação tem seguido dois caminhos: o modo como se assumem ou o modo como se recepcionam as informações provenientes dos veículos e objetos de pesquisa. É possível agregar a estes dois, ainda, um terceiro caminho: o da utilização dos veículos como ferramentas pedagógicas, o que implicou ensinar o que são estes veículos, 
quais as funções sociais que cumprem, como eles são produzidos, além de se analisar o poder ideológico, político e econômico que movimentam.

$\mathrm{Na}$ atualidade percebe-se um consenso a respeito de que não é possível compreender o funcionamento da cidadania e a participação nos projetos educomunicativos, partindo de um modelo de comunicação ancorado num ideal normativo distanciado da realidade social e seu verdadeiro contexto, e ecossistemas de comunicação específicos (LINÃRES FLEITE, 2014). Isto implica em primeiro lugar diagnosticar a cultura dos participantes (sua identidade, potencial e barreiras para seu desenvolvimento), nesses projetos, assim como dos outros envolvidos na dinâmica desse processo (CHIBÁS ORTIZ, 2015). A cultura entendida como estilo de vida da região e comunidade é vista cada vez mais pelas experiências implementadas em Cuba como um fator essencial para o direcionamento estratégico e objetivos cotidianos dos projetos.

\section{CONTEXTO, SUBTEXTO E HIPERTEXTO}

Nas últimas seis décadas, Cuba tornou-se um país com trajetória social bastante diferente dos outros países da América Latina. Com o triunfo da Revolução Cubana, liderada por Fidel Castro em 1959, e a adoção do regime socialista, Cuba tomou, involuntariamente, um caminho que a afastou de muitas das discussões, debates e práticas que aconteciam no resto do mundo. Mas não foi exatamente assim no caso da Educomunicação.

Sempre existiu uma forte preocupação do governo quanto à educação, razão pela qual se investiu, sempre que possível, no conhecimento de disciplinas científicas que nutrem a prática pedagógica. Mas até a década de 1980, vivenciou-se nas ciências humanas em geral, isto é, na Educação, na Comunicação, na Psicologia, na Filosofia, na Sociologia e na Administração, uma forte tendência pela utilização de autores provenientes do leste da Europa, do chamado bloco socialista. Os autores que não pertenciam a este bloco eram tratados com uma postura bastante crítica. Por outro lado, as ideias do educador Paulo Freire, por razões ideológicas e científicas, foram muito bem recebidas nos ambientes educacionais cubanos. E é, precisamente, por essa via oficial, junto com os contatos informais entre intelectuais de diversos países, que entram em Cuba as ideias que caracterizam a Educomunicação.

\section{NOVO CENÁRIO: INTERTEXTO}

$\mathrm{Na}$ atualidade, o surgimento e desenvolvimento de novas linguagens, mediadores e veículos de comunicação em espaços escolares, extraescolares, de lazer e privados, pelos diversos atores sociais e comunitários tem levado a profundas mudanças na configuração das subjetividades e das relações sociais (CITELLI, 2011). A sociedade cubana, mesmo com suas limitações tecnológicas, produzidas pelo bloqueio econômico e por outros fatores internos de ordem administrativa, não tem ficado fora deste processo. Não por acaso, um dos blogs mais visitados do mundo (mais de um milhão de visitantes por mês), considerado um dos blogs mais influentes na atualidade, é o conhecido Generación Y (Geração Y), de autoria da jornalista Yoani Sanchez (HIJUELOS, 2013). 
Surgiram outras formas de se produzir cultura cotidiana e interagir com ela (AGUADED, 2005). Mesmo com o relativamente baixo número de celulares existentes entre a população cubana, atualmente qualquer pessoa com um celular pode fazer uma foto ou um vídeo criativo e postar na rede mundial, informando sobre a realidade nacional, influenciando outras pessoas, além dele próprio construir um diferente olhar, comparando-se o espelho presencial ao virtual. Embora o número de computadores conectados à rede seja ainda muito baixo nas residências, existem computadores conectados em escolas ou instituições públicas, permitindo à população entrar em contato com o mundo. Se faz um uso comunitário dos correios eletrônicos, de forma tal que as pessoas que tem acesso a esse serviço servem de ponte, para que quem não possui acesso a web, possa enviar por meio dele e-mails e informações. Existe também o chamado pacote, que são um conjunto de filmes, seriados, notícias e informações úteis que são baixadas e distribuídas semanalmente entre algumas pessoas. É uma espécie de Internet off line. As pessoas podem, portanto, aproveitar as novas tecnologias, ainda que para isso tenham de se apoiar em quem tem acesso em ambiente de trabalho, de casa ou outros. Recentemente foram disponibilizados na Havana, em lugares públicos, espaços que permitem o acesso a Internet sem fio via wi-fi. As dificuldades cotidianas e a cultura coletivista fomentada pelo próprio governo cubano, facilitam a manifestação desses comportamentos.

\section{OS PROJETOS ESCOLARES, O TEXTO}

Para Martin Barbero (2002), um dos traços que caracterizam o ecossistema da comunicação atual é o surgimento de um ambiente educacional descentrado do sistema educacional formal (a escola clássica, sustentada pelo espaço físico da escola, o livro e o professor), para a dispersão e a fragmentação, deslocando-se para fora dos lugares anteriormente consagrados como tradicionalmente detentores do poder. Embora com suas peculiaridades, nota-se também que este processo ocorre na sociedade cubana atual.

As novas gerações de cubanos têm acesso direto à informação e ao conhecimento sem passar pela mediação dos adultos, por meio da conexão direta com as novas tecnologias. Esta é uma experiência que favorece a aquisição de habilidades necessárias para gerenciar as novas formas de comunicação, uma aprendizagem natural, que muitas vezes permite aos jovens tornarem-se produtores de seu próprio discurso na mídia. Mesmo com as limitações tecnológicas próprias do país, esta nova onda tem possibilitado ampla repercussão na escola cubana. Assim, é possível observar em diversas pesquisas como as crianças e adolescentes utilizam as novas tecnologias da comunicação ou qual seria seu desejo de utilizá-las (RIVERO, 2008). Por essa razão, os projetos pedagógicos formais e não formais estão tentando se adaptar a essa nova realidade (ROSA, 2008).

\section{OS PROJETOS EXTRAESCOLARES, O OUTRO TEXTO}

Como aconteceu em outros países, inicialmente (entre as décadas de 1960 e 1970) os projetos de caráter educativo que utilizavam os meios de comunicação adotavam o modelo hipodérmico, segundo a qual o emissor transmite informações que são aceitas de maneira passiva pelo 'receptor`, quando não uma perspectiva hipercrítica, segundo a 
qual os meios de comunicação de massa eram os eternos culpados por tudo, desconhecendo-se o papel de sujeito ativo do receptor (FIGARO, 2011).

Num segundo momento, já a partir da década de 1980, a maioria dos projetos educomunicacionais em Cuba optava por outras formas de operar, que levassem em consideração a identidade, a experiência, a criatividade e a competência comunicativa dos receptores, assim como a natureza dinâmica e negociada da comunicação. Estas novas formas de intervir foram implementadas em muitos dos projetos culturais comunitários com caráter educomunicativo desenvolvidos em Cuba nas últimas décadas, mesmo que muitas vezes os seus gestores-facilitadores não fossem conscientes desta mudança de paradigma comunicacional (CHIBÁS ORTIZ, 2015).

Os projetos educomunicativos criaram espaços que permitiram o debate sobre temas polêmicos da sociedade cubana e internacional que não eram colocados na grande mídia cubana (rádio e televisão). Também funcionaram como espaços criativos, dada a própria característica que eles adotaram no país, mais direcionados ou se apoiando nas manifestações artísticas e culturais, como artes plásticas, cinema, teatro e outras.

\section{EDUCOMUNICAÇÃO NA PRÁTICA}

Em Cuba podemos apreciar três tipos de experiências educomunicativas: primeiro, as vinculadas a instituições do governo e a estruturas internacionais; segundo, as vinculadas a projetos originados na academia; e a terceira referente aos projetos independentes.

No referente a primeira tendência podemos dizer que, diferentemente de muitos países latino-americanos, onde a prática educomunicativa esteve mais ligada a iniciativas de instituições privadas; projetos independentes e Organizações não-governamentais (ONGs) tiveram um papel central em Cuba em instituições governamentais gerenciadas pelo Ministério de Educação (MINED), Ministério de Educação Superior (MES) e pelo Instituto Cubano de Arte e Industria Cinematográfica (ICAIC) e pela União de Escritores y Artistas de Cuba (UNEAC). Observa-se uma situação semelhante em vários países da Europa e nos Estados Unidos, onde a prática educomunicativa integra os planos de ensino formais. Poder-se-iam mencionar, também, os casos da Inglaterra e da França, onde a Educomunicação é uma disciplina opcional no ensino primário e no secundário, enquanto na Dinamarca, Finlândia, Noruega e Espanha ela é uma disciplina facultativa (RIVERO, 2010).

Mesmo com sua presença na educação formal e com este peso governamental, em Cuba também foram fomentados projetos educomunicativos não formais, mas quase sempre com o suporte de alguma entidade estatal. É o caso dos projetos educomunicativos que surgiram em torno do ICAIC e da UNEAC.

Mas, as primeiras ações de educação para a análise das mídias, da forma como ocorreu em outros países da América Latina, remontam ao Plano DENI (Plano de Educação para a Infância), divulgado em 1969 pela Oficina Católica Internacional de Cine (Escritório Católico Internacional de Cinema), também conhecida pelas suas siglas OCIC, para a formação de um espectador responsável, crítico, criativo e participativo, 
por meio de atividades em grupo, que combinam a avaliação com a realização de obras cinematográficas (RAMOS, 2001). Eles foram baseados na conceituação da Linguagem Total (VALLET, 1977), que considera além da linguagem verbal, o som e os efeitos visuais, funcionando de tal modo que dentro da comunicação cada pessoa seja emissora e receptora ao mesmo tempo. A implementação deste plano em Cuba nas últimas décadas tornou-se possível por meio de várias experiências, em especial a feita com crianças por Pablo Ramos, apoiando-se também no ICAIC (RAMOS, 2005).

Inicialmente, pode-se citar o Projeto Gemini, que funcionou entre 1994 e 2000 para a aplicação dos princípios da Convenção sobre os Direitos da Criança e coordenado pela rede "O universo audiovisual da Criança Latino-americana", a cargo de Raisa Labrada e Pablo Ramos, dirigida a crianças e adolescentes com o duplo objetivo de compreender a linguagem visual e, por sua vez, refletir sobre questões de educação para a cidadania e crescimento pessoal (direitos da criança, meio ambiente, saúde, sexualidade, violência nos meios de comunicação e outras áreas onde os conflitos foram identificados).

Dessa forma, a Educomunicação em Cuba tem se desenvolvido fundamentalmente a partir das experiências que utilizavam o cinema como mediação tecnológica. A partir da década de 1970, lideradas, de um lado, por Pablo Ramos entre outros, e de outro, pela prática dos projetos culturais comunitários, coordenados pela UNEAC a partir do ano 1994, desencadeou-se o movimento dos coordenadores de projetos comunitários. Neste movimento, um reconhecido artista ou escritor liderava em seu próprio bairro um projeto cultural relacionado com a manifestação artística, na qual era considerado expert. Inicialmente, começaram 25 projetos, mas de acordo com os dados colhidos em 2012, existiam em torno de 298 (CHIBÁS ORTIZ, CASTRO ORTIZ, 2012). Muitos desses projetos podem ser classificados como projetos educomunicativos (um total de 27). Os critérios para classificar esses projetos, tendo ou não um caráter educomunicativo, são explicados abaixo quando apresentamos os parâmetros seguidos pelos projetos educomunicativos em Cuba. Vejamos a seguir o Quadro Projetos culturais responsáveis (caso UNEAC):

O segundo tipo de experiências de trabalho educomunicativo em Cuba, está integrado pelas pesquisas e trabalhos práticos derivados dos estudos de Criatividade desenvolvidas nos ambientes acadêmicos, com destaque para os trabalhos desenvolvidos pelo Prof. Gerardo Borroto. As experiências que realizou Pablo Ramos junto com a Igreja Católica começaram há uns 30 anos com o apoio do ICAIC. Estas últimas focaram mais o público infanto-juvenil e utilizaram mais os meios audiovisuais e, fundamentalmente, o cinema, enquanto que as pesquisas e experiências de Borroto, sediadas no CREA (Centro de Referência para a Educação de Avançada) da CUJAE (Instituto Superior Jose Antonio Echevarria) começaram na década de 1990, focando mais o ensino universitário propriamente dito, com ênfase no público adulto e utilizando com fins educativos o ensino a distância em AVAs (Ambientes Virtuais de Aprendizagem). A partir de 2015 como parte de seu projeto de pesquisa-ação, Gerardo Borroto e seus alunos do programa de mestrado e doutorado do CREA, também desenvolveram no bairro de Pogolotti, comunidade carente da cidade de Havana, experiências de educação para os meios digitais e presenciais com uma leitura crítica da realidade e empoderamento da identidade local, utilizando dispositivos móveis. 
Outro exemplo de projeto educomunicativo não formal com participação de instituições governamentais cubanas, que tem sua origem ligada a instituições acadêmicas, é a experiência Escaramujo, projeto que funciona desde 2010 coordenado pelas Faculdades de Comunicação e Psicologia da Universidade de Havana e o Ministério do Interior de Cuba, que envolve também a Faculdade de Comunicação da Universidade de Oriente e a Faculdade Latino-americana de Ciências Sociais (Flacso-Cuba). Este projeto tenta reintegrar na sociedade crianças e adolescentes com problemas de conduta antissocial utilizando as ferramentas da Educomunicação (ROMERO REYES, 2015).

Também pode ser citado como uma experiência que utiliza a perspectiva educomunicativa o projeto Desenvolvimento Social integral e participativo dos Adolescentes de Havana Velha, que funciona desde 2011, como parte de uma aliança estratégica entre a UNICEF (Escritório das Nações Unidas para a Infância) em Cuba e a OHCH (Escritório do Historiador da Cidade). Este projeto, que foca o público adolescente do município havanero conhecido como Havana Velha, região que foi declarada patrimônio da Humanidade pela UNESCO, alberga por sua vez outros diversos projetos menores que tem por objetivo implementar, através das diversas manifestações artísticas, esportivas e outras práticas de índole social, o desenho e consolidação de ações que fomentem a identidade individual e coletiva de crianças e adolescentes. Para conseguir este objetivo parte-se da perspectiva da Educomunicação, dentre outras fontes teórico-práticas (LOPÉZ DIÁS, 2012).

Mas existe uma terceira tendência ou tipo de prática educomunicativa que podemos apreciar em Cuba. Junto com as iniciativas descritas, que possuem em alguns casos uma projeção institucional e em outras semi-institucional, também surgiram nos bairros projetos independentes como o do Callejón del Hamel, liderado pelo artista plástico Salvador Gonzalez Escalona, que não está vinculado diretamente a nenhuma instituição governamental. Este projeto ensinou crianças e jovens carentes a pintar e criar obras plásticas em toda a rua de um bairro carente de Havana, além de inserir outras manifestações artísticas no cotidiano destes bairros e contribuir para desenvolver nos participantes do projeto a autoestima, uma identidade cultural própria, embasada fundamentalmente na cultura afrocubana e um olhar crítico sobre a realidade.

Além das ações geradas a partir da igreja católica, UNEAC, Universidade de Havana em coordenação com outras entidades e a CUJAE, que permanecem até hoje, destacam-se outras igualmente bem-sucedidas. Como exemplo, pode-se citar o workshop La Linterna Mágica (A Lanterna Mágica), entre os anos 1988 e 1991, no Palácio Central de Pioneiros Ernesto Che Guevara, durante o ano letivo. Foi proposto, na primeira fase, despertar o interesse do público com a análise dos filmes e desenvolver alguns conhecimentos técnicos e estéticos associados a este ramo, enquanto que na segunda fase, adentrou-se já no processo criativo propriamente dito, com a produção de um filme animado. Essa experiência também foi realizada na capital, nos cinemas Elpidio Valdés por iniciativa do Ministério de Cultura.

Também, a partir da década de 1980, criaram-se cineclubes em todo o país para debater sobre os filmes no próprio cinema, em horários não comerciais, por iniciativa do ICAIC e do Ministério de Cultura. Todos estes esforços demonstram uma continuidade nas ações encaminhadas a educar para os meios. 


\section{A OPERACIONALIZAÇÃO DOS PRINCÍPIOS DA EDUCOMUNICAÇÃO EM CUBA}

Mesmo que de forma intermitente e não de uma maneira unânime, a operacionalização da Educomunicação em Cuba, por meio da criação e manutenção de ecossistemas criativos abertos nos projetos formais (nas escolas) e não formais (fora das escolas), seguiu de forma geral estes parâmetros (CHIBÁS ORTIZ, 2012).

- Colocar no centro do processo ensino-aprendizagem um veículo de comunicação como peça chave nas mãos dos alunos, utilizando-o como instrumento para a análise da realidade e construção conjunta e criativa de novas mediações. Passando dessa forma, da análise da linguagem original dos veículos à criação de novas linguagens.

- Inserir o jovem no mundo (ideológico-filosófico). Ênfase na análise social, nos valores e não na tecnologia.

- Desenvolver no instrutor posturas e funções diferentes das tradicionais. A postura do tutor não deve ser a de detentor do conhecimento e sim da dialógica, a fim de estimular a participação de todos. O tutor, por sua vez, deve ser um mediador e facilitador do processo docente. A postura do tutor, portanto, deve ser a de mostrar um interesse comedido, mas explícito, pelo dia a dia e as preocupações cotidianas dos alunos, assim como pela forma em que os conteúdos do curso estavam sendo aplicados. (não entendi este interesse comedido e explícito)

- Enfatizar, por parte do instrutor-facilitador, a pesquisa e a construção conjunta do conhecimento, outorgando a responsabilidade do aprendizado ao aluno.

- Negociar os principais temas e bibliografia que serão objeto de debate, durante o curso ou desenvolvimento do projeto desde o primeiro encontro.

- Criar uma comunidade de aprendizagem e estabelecer vínculos afetivos que devem ser construídos desde os primeiros contatos entre o facilitador e os alunos/participantes.

- Além dos veículos de comunicação tradicionais existentes, fechados para os alunos/participantes, os alunos devem criar ou apropriar-se de veículos de comunicação próprios, onde se publicaram os trabalhos e resultados do curso ou debates realizados, oferecendo-se feedback entre eles. Esta seria uma forma de testar as ideias com o 'mundo'. Estes veículos são administrados pelos alunos, mas monitorados pelo tutor, que cobra a participação de todos.

- Estimular a reflexão sobre como funciona a criação e manutenção de um veículo e sobre como elaborar os conteúdos.

- Estimular a cooperação e uma sadia interdependência por meio de tarefas coletivas que implicam pesquisa conjunta e atividades colaborativas.

- Evitar tarefas e debates com perguntas fechadas ou de alternativas. Portanto, utilizar mais tarefas com perguntas abertas, dissertativas.

- Estimular a criatividade, por meio da utilização nas reuniões do grupo de técnicas de criatividade, como o Brainstorming, Método das nove janelas, entre outros. Incentivam-se os olhares e leituras diferentes da realidade, assim como o novo na estruturação da forma e do conteúdo nos veículos de comunicação gerenciados pelos alunos/participantes. 
- Promover situações para que os participantes desenvolvam análises, referentes a situações reais que estejam acontecendo na vida, no momento relativo aos temas do curso ou projeto.

- Promover análises dos participantes, não apenas dos conteúdos objeto do curso ou projeto, mas, também, sobre a metodologia ou maneira em que estes foram disponibilizados.

- Incentivar o debate por meio de perguntas abertas feitas pelo instrutor-facilitador, sobre a relação dos temas do curso com a responsabilidade socioambiental.

- Declarar, por parte do instrutor-facilitador, o seu interesse e compromisso em que os alunos/participantes obtenham bom resultado.

- Avaliar, com outra finalidade e diferente da forma tradicional (usando o próprio veículo de comunicação criado e mantido pelos alunos como instrumento de avaliação). Ênfase durante a avaliação no aspecto qualitativo, e não no quantitativo; portanto usar perguntas dissertativas e menos questões teste. Utilizar tarefas que envolvam a avaliação coletiva e individual, assim como a autoavaliação.

Muitos dos projetos comunitários da UNEAC podem ser classificados como estando dentro de uma perspectiva educomunicativa, dado que cumprem com muitos desses parâmetros. A utilização de um veículo de comunicação de caráter artístico como centro do ensino, sendo ele uma peça de teatro, uma pintura, música ou texto literário é o que caracteriza os trabalhos da UNEAC.

Numa pesquisa feita por Rivero (2010), apresenta-se uma primeira aproximação ao estado atual das experiências de Educomunicacão. Este estudo considerou as experiências que abordaram os meios de comunicação clássicos, tais como cinema, televisão e vídeo, e identificou 15 organizações e 25 experiências de natureza formativa, com diferentes graus de institucionalização e formalidade dos espaços educomunicativos. Percebeu-se um alto grau de institucionalização, persistindo um grande peso do Estado na geração de ações educomunicativas.

Outro estudo dos resultados da pesquisa realizada por Rivero (2010) mostra que a maioria dos projetos educomunicativos em Cuba é de caráter artístico cultural. Isto se deve em boa medida à tradição do país neste campo, assim como a fatores conjunturais e políticos de enfrentamento direto com os materiais audiovisuais provenientes do exterior que levaram a direção política do país a reforçar a identidade nacional, embasando-se na cultura artístico-literária.

No levantamento feito por este autor, quanto aos projetos da UNEAC focando as mediações tecnológicas digitais via Internet, observou-se que de 298 projetos comunitários, apenas 27 estavam na rede. Destes, 24 tinham realmente um caráter profundamente educomunicativo (CHIBÁS ORTIZ; CASTRO ORTIZ, 2012). Estes elementos afirmam que ainda existe um amplo caminho para ser trilhado, antes de se poder realmente aproveitar as novas tecnologias com um sentido educomunicativo.

Observa-se, também, que a questão educomunicacional possui um maior interesse por parte das entidades oficiais de perfil cultural, como a UNEAC e o ICAIC, do que as acadêmicas ou escolares. Muitas das ações educomunicativas que são desenvolvidas no espaço físico das escolas, não fazem parte do currículo escolar e são geradas pelo interesse individual dos professores e alunos. 


\section{APONTAMENTOS PARA DESENVOLVER A EDUCOMUNICAÇÃO EM CUBA}

As seis áreas descritas por Soares (2011) como portas de ingresso na Educomunicação são: 1. Educação para a comunicação; 2. Expressão comunicativa por meio das artes; 3. Mediação tecnológica nos espaços educativos; 4. Pedagogia da comunicação; 5. Gestão da comunicação; 6. Reflexão epistemológica sobre a Educomunicação. Destas áreas, observa-se que se desenvolveram em Cuba principalmente. Este panorama deixa espaço para um investimento maior na reflexão e aplicação prática das outras áreas da Educomunicação, ainda não desenvolvidas no país.

Embora, ainda haja muito para se construir, a fim de tornar a Educomunicação um espaço sólido e rigorosamente estabelecido em Cuba, existem condições favoráveis, que podem auxiliar na condução desse processo, tais como:

- Alto grau de institucionalização do Estado neste campo.

- Alto grau de reconhecimento social da escola cubana na sociedade.

- Alto grau de instrução, educação e cultura da população cubana em geral e dos instrutores-facilitadores em particular.

- Histórico de sucesso, expressando alguma continuidade no tempo, que deixou uma marca positiva na dinâmica educomunicativa no país.

- Grande envolvimento emocional das pessoas nessas ações, apesar das dificuldades materiais que enfrentam.

No entanto, considera-se que esses potenciais às vezes são bloqueados pela falta de um conhecimento profundo de especificidades e necessidades das novas gerações por parte das instituições que fomentam projetos educomunicativos.

Tem-se tornado visível em outros países que a escola, instituição de ensino formal, não tem acompanhado a necessidade de resposta para o público, principalmente jovem. Por este motivo, outras entidades, também estatais, como o ICAIC, a UNEAC e o Ministério de Cultura, tentam suprir esta carência. Portanto, é necessário a escola cubana continuar e aperfeiçoar este papel de liderança das práticas educomunicativas, assumindo um conceito mais amplo de Educomunicação e fomentado práticas mais afins com ele.

Recomenda-se fazer um levantamento das barreiras culturais à comunicação que enfrenta cada projeto educomunicativo para assim poder propor caminhos e alternativas para superá-las de forma orgânica e com soluções criativas específicas. Sugere-se inserir a Educomunicação, como disciplina - em toda sua diversidade e formas de aplicação -, nas escolas e universidades. Também deve-se fomentar mais a presença de projetos que, a partir da perspectiva da educação não formal, fora da escola, contribuam ao desenvolvimento da participação individual e coletiva, assim como ao crescimento da autoestima e surgimento de novas identidades pessoais e comunitárias compromissadas com a mudança, a criatividade social e a participação, contribuindo a fomentar a comunicação com visão crítica e participativa dos envolvidos. A criação é a marca registrada da formação educomunicativa, sob a premissa de que a melhor maneira de aprender é fazendo. 


\section{REFERÊNCIAS BIBLIOGRÁFICAS}

AGUADED, José Ignacio. Estrategias de edu-comunicación en la sociedad audiovisual, Comunicar, n. 24, p. 35-34, 2005.

BRAGA, José Luiz, e CALAZANS, Regina. Comunicação e Educação: questões delicadas na interface. São Paulo: Hacker, 2001.

CHIBÁS ORTIZ, Felipe; CASTRO ORTIZ, Mileidy. Complejidad y creatividad sostenible a través de herramientas de internet en proyectos culturales y educativos, In: Anales del Congreso Complejidad, p. 234-244, 2012.

CHIBÁS ORTIZ, Felipe. Educomunicação na gestão educacional criativa em projetos corporativos EAD: um estudo de caso, In: Revista Científica Hermes, v. 6, p. 77-97, 2012.

CHIBÁS ORTIZ, Felipe. Creatividad, Comunicación y Cultura: gestión innovadora de proyectos educativos-culturales en la era digital, La Habana: Pueblo y Educación, 2015. 340 p. ISBN: 978-95913-2906-6.

CITELLI, Adilson Odair. Comunicação e Educação: implicações contemporâneas. In: CITELLI, Adilson Odair; COSTA, Maria Cristina (Eds.), Educomunicação, construindo uma nova área do conhecimento, São Paulo: Paulinas, 2011.

FIGARO, Roseli. Estudos de recepção para a crítica da comunicação. In: CITELLI, Adilson Odair; COSTA, Maria Cristina (Eds.), Educomunicação, construindo uma nova área do conhecimento, São Paulo: Paulinas, 2011.

HIJUELOS, Oscar. Heróis epioneiros (Entrevistaà YoaniSanchez), Jornal Times, 12 de maio, 2008. Disponívelem:<http://www.time.com/time/specials/2007/article/0,28804,1733748_1733756_1735878,00. html>. Acesso em: 20.5.2013.

HUERGO, Jorge. Comunicación/Educación: Itinerarios transversales. In: VALDERRAMA (Eds.) Comunicación-Educomunicación: coordenadas, abordajes y travesías, Bogotá: Universidad Central/ Siglo del Hombre, 2000.

LINÃRES FLEITE, Cecilia. Cultura y participación desde el desarrollo humano: instancias de innovación y ejes del cambio. In: MORAS PUIG, PEDRO EMILIO;

RIVERO, YISEL (Eds.) Participación cultural de la adolescencia en Cuba: Expresiones y claves para su comprensión, La Habana: Centro de Investigaciones Culturales Juan Marinello y UNICEF, 2014. LOPEZ DÍAZ, Karen e otros. La adolescencia en La Habana Vieja: Su estado actual, La Habana: Unión Europea, UNICEF y Oficina del Historiador de la Ciudad, 2012.

MARTÍN BARBERO, Jesús. Jóvenes: comunicación eidentidad, Pensar Iberoamérica, n. 0, febrero, 2002, $<$ http://www.oei.es/pensariberoamerica/numero0.htm>. Acesso em: 23.4.2013.

RAMOS, Pablo. Tres décadas de Educomunicación en América Latina: los caminos del Plan DENI, (CD-Rom), Quito: OCLACC, 2001.

RAMOS, Pablo. De la educación cinematográfica a la educación para la comunicación en Cuba. Comunicar, n. 24, Ano XIII, p. 113-116, mar. 2005.

RIVERO, Yisel. Escenario educomunicativo en Cuba. Posibilidades y desafíos, Informe de investigación, La Habana: 2008.

RIVERO, Yisel. Pensar la educación audiovisual infanto-juvenil en Cuba. Acercamiento desde sus experiencias. Perfiles de la cultura cubana. n. 5, jun-oct, 2010.

ROMERO REYES, Rodolfo. Educomunicación popular: camino que se abre paso desde Cuba, Revista Estudios del Desarrollo Social: Cuba y América Latina. v. 3, n. 3, p. 25-35, sep.-dic. 2015. Disponível em: <http://www.revflacso.uh.cu/index.php/flacso/article/view/144/159>. Acesso em: 12.12.2015 
ROSA, Yeidy. Hacia una pedagogía multimedial: el caso de pintacuentos In: Ramos, Pablo y Aylinn. Torres (Eds.) El audiovisual y la niñez, La Habana: Ediciones ICAIC, 2008.

SOARES, Ismar de Oliveira. EaD como prática educomunicativa: Emoção e racionalidade operativa, Núcleo de Educação e Comunicação da Universidade de São Paulo, p. 1-28, 2003. Disponível em: $<$ http://www.usp.br/nce/wcp/arq/textos/3.pdf>. Acesso em: 27.11.2012.

SOARES, Ismar de Oliveira. Caminos de la educomunicación: utopias, confrontaciones, reconocimientos, Nomadas, n. 30, p. 194-207, abr., 2009. Disponível <http://www.ucentral.edu.co/ images/editorial/nomadas/docs/nomadas_30_14_d_caminos_de_la_educomunicacion.pdf $>$. Acceso: 12.12.2015.

SOARES, Ismar de Oliveira. Educomunicação, o conceito, o profissional, a aplicação. São Paulo: Paulinas, 2011.

SOARES, Ismar de Oliveira. Introdução à edição brasileira: A educomunicação na América Latina: apontamentos para uma história em construção. In: APARICI, Roberto. Educomunicação para além de 2.0, São Paulo: Paulinas, 2014.

UNESCO. La educación en materia de comunicación, Paris: UNESCO, 1984.

VALLET, Antoine. El lenguaje total. Zaragoza: Luis Vives, 1977.

\begin{tabular}{|c|c|c|}
\hline \multirow[b]{2}{*}{ INDICADOR } & \multicolumn{2}{|c|}{ PARADIGMA } \\
\hline & $\begin{array}{l}\text { EDUCACIONAL } \\
\text { TRADICIONAL }\end{array}$ & EDUCOMUNICATIVO \\
\hline Valores predominantes & $\begin{array}{l}\text { Tradição, hierarquia, regras, } \\
\text { individualismo }\end{array}$ & $\begin{array}{l}\text { Criatividade, Participação, Compro- } \\
\text { misso ideológico, Responsabilida- } \\
\text { de Social e ambiental, coletivismo }\end{array}$ \\
\hline $\begin{array}{l}\text { Veículo de comunicação con- } \\
\text { trolado pelos alunos }\end{array}$ & Não disponibiliza & Disponibiliza \\
\hline Estimula & Dependência e obediência & Autonomia e criatividade \\
\hline Gestão Participativa & Não utiliza & Utiliza \\
\hline Parcerias, alianças, patrocínios & Não explora & Explora \\
\hline Visão do processo educativo & $\begin{array}{l}\text { Parcial (interno vs. externo/ } \\
\text { gestores vs. professores) }\end{array}$ & $\begin{array}{l}\text { Integral (interno e externo/ gestores } \\
\text { com professores) }\end{array}$ \\
\hline Tarefas & Individuais, competitivas & $\begin{array}{l}\text { Coletivas cooperativas e interde- } \\
\text { pendentes }\end{array}$ \\
\hline Olhar inter e transdisciplinar & Não utiliza & Utiliza \\
\hline Postura do instrutor & Reativa & Proativa \\
\hline Estilo de liderança & Autoritário e centralizador & Democrático e descentralizador \\
\hline $\begin{array}{l}\text { Clima de trabalho/Gestão dos } \\
\text { afetos }\end{array}$ & Distante & $\begin{array}{l}\text { Confiança, estimula laços afetivos } \\
\text { profundos }\end{array}$ \\
\hline Comunicação integrada & Não possui & Possui \\
\hline Barreiras à comunicação & Muitas & Poucas \\
\hline $\begin{array}{l}\text { Novas tecnologias e redes so- } \\
\text { ciais }\end{array}$ & Explora pouco & Utiliza bastante \\
\hline Avaliação & Individual feita pelo professor & Individual, coletiva e auto-avaliação \\
\hline
\end{tabular}


Projetos comunitários ativos em 1994

Projetos comunitários ativos em 2012

Projetos comunitários na Internet em 2012

Forma em que estão presentes os projetos da UNEAC na Internet

Projetos com endereço web 2

Projetos nas redes sociais 1

Projetos com blog 0

Projetos com página "Quem Somos" 24

Projetos com caráter educomunicativo 27

QUADRO 2

Projetos Culturais Responsáveis (Caso Uneac) - Resumo Estatístico

Fonte: Sitio Web UNEAC (acessado: 12/02/2012) 